\title{
Prevalence of Antibiotic Resistance in Clinical Strains of $E$. Coli and Their Control
}

\author{
Sujatha. $\mathrm{J}^{1}$, Anusuya.P $\mathrm{P}^{2}$ \\ I(PG and Research Department of Microbiology, Sri Akilandeswari Women's College / Thiruvalluvar \\ University, India) \\ ${ }^{2}$ (PG and Research Department of Microbiology, Sri Akilandeswari Women's College / Thiruvalluvar \\ University, India)
}

\begin{abstract}
The present study was to evaluate the isolates of antibiotic resistant E. coli in clinical samples and their control. A total of 50 E. coli strains were isolated from samples such as ENT, Pus and UTI. 5 different antibiotics were tested. $20 \%$ of the strains showed resistance to single antibiotic (AMP, AMX), whereas rest of the strains to 2-5 antibiotics (i.e.) AMP-AMX (6\%); AMP-AMX-CXM (16\%), AMP-AMX-CN (20\%), AMP$A M X-C N-C P D(20 \%)$, and AMP-AMX-CXM-CN-CPN (18\%). MAR index for the isolates was found to be from 0.4-1.0. $4 \%$ of the strains showed a MAR index of 0.4 and $20 \%$ strains showed a MAR index of 1.0. The presence of ESBL production in various E.coli strains which was indicative through exhibition of resistance to first, second as well as third generation cephalosporin. Among 50 strains, 30 strains (60\%) were observed to possess CTX type of $\beta$-lactamases. $62 \%$ of clinical strains were positive for haemolysis. Among them 20 (87\%) of them were from UTI samples, 5 (29.41\%) of them were from ENT samples and 6 (60\%) of them were from Pus samples. Plasmid profile of the E.coli isolates was found to be $>23 \mathrm{~kb}$. All the resistant strains tested against $\beta$-lactam antibiotics, lost resistance during plasmid curing.
\end{abstract}

Keywords: E.coli, Haemolytic, $\beta$-lactam, Antibiotic resistance

\section{Introduction}

The increase in fecal pollution in source water is a menace not only in developing countries but also in developed countries. Water borne bacterial pathogens viz., E.coli, Salmonella, Shigella and V.cholerae can lead to outbreak of intestinal diseases and result in serious health implications as well as economic loss. Improper management of sewage as well as industrial wastes and their entry in to the water ways finally pollute the coastal waters.

Most populated cities as well as most of the industrial units are located either on the banks of the rivers (or) nearer to the coastal cities and this situation holds good worldwide. Few studies demonstrated statistically significant correlation between industrial pollution and the spatial distribution of antibiotic resistance (Goniurriza et al., 2000 and McArthur and Tuck field, 2000). Heavy use of antibiotics for medical and veterinary purposes (White et al., 2000 and Balague and Vescovi, 2001) as well as the domestic and agricultural use of pesticides and related compounds (Balague and Garcia Vescovi, 2001) caused significant antibiotic contamination of the natural environment and consequent development of resistantance in communities.

The resistance developing in one part of the country, or indeed in the world, can be disseminated readily (Greenwood, 1998). The problem of microbial drug resistance is a major public health concern due to its global dimension and alarming magnitude. The major resistance issues overall are, those which are related to the methicillin-resistant Staphylococcus aureus (MRSA), vancomycin resistant enterococci (VRF), extendedspectrum $\beta$-lactamase producing Enterobacteriaceae, and the multidrug-resistant P.aeruginosa and Acinetobacter baumannii (Rossolini and Mantengoli, 2008). In the present investigation E. coli, an emerging pathogen was dealt with regarding its antibiotic resistance in the clinical resistance environment.

Resistance mechanisms can either be an intrinsic property of a bacterial species or an acquired trait. Acquired resistance occurs as a result of chromosomal mutations or by the acquisition of genetic elements. Intrinsic resistance covers a whole bacterial species and provides resistance without the addition of genetic elements or mutations.

The $\beta$-lactamases execute their effect in hindering the work of $\beta$-lactams by hydrolyzing the $\beta$-lactam ring structure (Goering, 2008 and Bush, 2010). These can be encoded on both plasmids and chromosomes (Poole, 2004; Goering et al., 2008 and Bush, 2010). The plasmid-encoded $\beta$-lactamases are related to the chromosomally-encoded enzymes (Jacoby, 2009). B-lactamases can be transferred within different bacteria (Poole, 2004 and Bonnet, 2004). The $\beta$-lactamases are mostly extracellular in Gram-positive bacteria, while periplasmic in Gram-negative species (Goering et al., 2008 and Bush, 2010). Enterobacteriaceae are the significant causes of serious infection, and many of the most important members of this family are becoming increasingly resistant to currently available antimicrobials. Two organisms of concern are E. coli and Klebsiella 
pneumoniae, opportunistic pathogens of humans and animals are responsible for a wide range of infections, such as urinary tract infections, pneumonia, wound infections and septicemia (Slama et al., 2010). The present study was to evaluate the isolates of antibiotic resistant E. coli in clinical samples and their control.

\section{Collection of clinical samples}

\section{Materials And Methods}

Clinical samples (25 nos. were collected from hospitals located in Chidambaram (Cuddalore district) area using sterile containers and were brought to the laboratory and stored at $4^{\circ} \mathrm{C}$. All the samples were brought to the laboratory immediately and analyses were made within two hours of collection.

\section{Antimicrobial susceptibility testing}

Antibiotic susceptibilities of the isolates were determined by both well diffusion using Muller Hinton

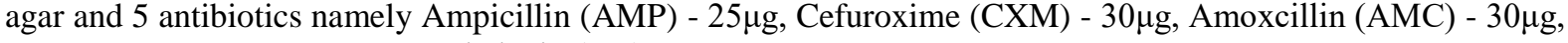

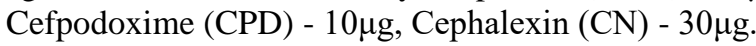

\section{Multiple antibiotic resistances (MAR) index}

The multiple antibiotic resistance (MAR) index of each strain was calculated according to the method described by Krumperman (1983) using the formula: $a / b$, where ' $a$ ' represents the number of antibiotics to which a particular isolate was resistant and ' $\mathrm{b}$ ' the total number of antibiotics tested.

\section{Disc susceptibility test to screen for ESBL}

All clinical isolates were screened for ESBL production using three indicator cephalosporins, namely ceftazidime $(30 \mu \mathrm{g})$, cefotaxime $(30 \mu \mathrm{g})$ and cefpodoxime $(30 \mu \mathrm{g})$. The isolates were considered to be resistant if the diameter of the inhibition zone for ceftazidime, cefotaxime or cefpodoxime was $\leq 22 \mathrm{~mm}, \leq 27 \mathrm{~mm}$ or $\leq 17$ $\mathrm{mm}$, respectively. The strains that showed resistance to at least one of the three cephalosporins were tested further using phenotypic confirmation methods as per Srisangkaew and Vorachit (2004).

\section{Double disc synergy test (DDST)}

E. coli isolates showing resistance to any of the three indicator cephalosporin's were tested for ESBL production by the DDST. Cefotaxime $(30 \mu \mathrm{g})$, cefuroxime $(30 \mu \mathrm{g})$, cefpodoxime $(30 \mu \mathrm{g})$ and

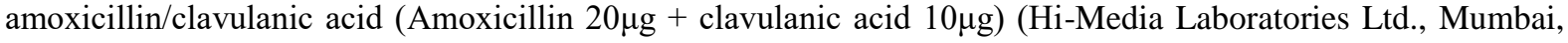
India) were used for ESBL detection (Datta et al., 2004 and Duttaroy and Mehta, 2005). Amoxicillin/clavulanic acid and third generation cephalosporin discs were placed at a distance of $20 \mathrm{~mm}$ from center to center on lawn cultures on Muller-Hinton agar plates. The plates were incubated at $37^{\circ} \mathrm{C}$ overnight. Any enhancement in zone of inhibition of cephalosporin towards the amoxicillin/clavulanic acid disc was considered a positive result for an ESBL.

\section{Haemolytic activity}

For detection of hemolytic activity, the E. coli isolates were grown on tryptose soy agar with $5 \%$ defibrinated sheep blood or $5 \%$ sheep erythrocytes washed in saline $(0.85 \%)$ with or without $10 \mathrm{mM} \mathrm{CaCl}_{2}$ or $10 \mathrm{mM}$ EDTA added. The blood agar plates were incubated at $37^{\circ} \mathrm{C}$ for $18-24 \mathrm{hrs}$ and then examined for the presence of haemolysis zones around bacterial colonies (Beutin et al., 1989).

\section{Plasmid isolation}

Plasmid DNA profiling of the strains was done by the alkaline lysis method (Sambrook et al., 1989). All bacterial strains were incubated overnight in $5 \mathrm{~mL}$ Luria Bertani broth at $37{ }^{\circ} \mathrm{C}$. The bacterial cells were collected by centrifugation at $10,000 \mathrm{rpm}$ for $5 \mathrm{~min}$. in a $1.5 \mathrm{~mL}$ micro centrifuge. To the pellet $100 \mu \mathrm{L}$ of glucose-Tris-EDTA buffer was added and completely re-suspended. To that $200 \mu \mathrm{L}$ of lysis buffer solution was added and mixed gently for $5 \mathrm{~min}$. The tube was spun at 10,000 rpm for $5 \mathrm{~min}$. and supernatant was transferred to a sterile eppendorf tube. Equal volume of phenol: chloroform was added vortexes, centrifuged at 10,000 rpm for 5 min and supernatant was transferred to a clean eppendorf tube. Plasmid DNA that extracted was precipitated and concentrated by using ice cold isopropanol. The resolution of the isolated plasmid DNA was checked on $0.8 \%$ agarose gel. $1 \mathrm{~kb}$ DNA ladder and Lambda DNA Hind III digest marker DNA were used as size standards (Fermentas).

\section{Plasmid curing}

The role of plasmids in the antibiotic resistance was confirmed by curing the plasmid with acre dines orange at a concentration of $500 \mu \mathrm{g} / \mathrm{ml}$ added to the nutrient broth. The culture was incubated at $37^{\circ} \mathrm{C}$ for $12 \mathrm{hrs}$ (Fugii et al., 1997). Antibiotic resistance patterns of the strains before and after curing of plasmids were compared. The curing was confirmed by loss of plasmid and antibiotic susceptibility testing using antibiotics to which organisms were resistant. 
Antibiotic Resistance of Clinical Strains

\section{Results}

In the present study 5 different antibiotics were tested to study the antimicrobial susceptibility of the E.coli isolates. Among the tested antibiotics Ampicillin and Amoxicillin were belong to $\beta$-lactams, whereas, cephotaxime, cephalexin, cefpodoxime respectively belong to first, second and third generation cephalosporines which are also considered group of $\beta$-lactams. A total of $50 \mathrm{E}$. coli strains were used for testing their antimicrobial susceptibility. Regarding susceptibility of $E$. coli, the resistant and sensitive patterns were tested to

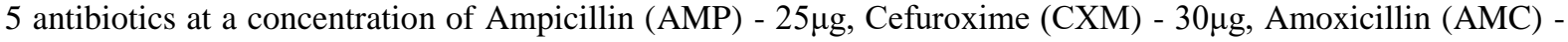

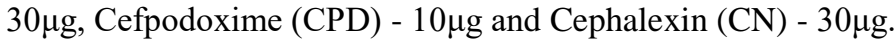

In the present study Ampicillin showed 100\% resistance followed by Amoxicillin (82\%), Cephalexin (58\%), Cefuroxime (54\%) and Cefpodoxime (38\%) (Table-1).

In the present study $20 \%$ of the strains showed resistance to single antibiotic (AMP, AMX), whereas rest of the strains to 2-5 antibiotics (i.e.) AMP-AMX (6\%); AMP-AMX-CXM (16\%), AMP-AMX-CN (20\%), AMP-AMX-CN-CPD (20\%), and AMP-AMX-CXM-CN-CPN (18\%) (Table-2).

In this study, MAR index for the isolates was calculated and the range was observed from 0.4-1.0. Among the tested isolates for multiple antibiotic resistance (MAR), $4 \%$ of the strains showed a MAR index of 0.4 and $20 \%$ strains showed a MAR index of 1.0 . The present study indicated the presence ESBL production in various E.coli strains which was indicative through exhibited resistance to first, second as well as third generation cephalosporins. Among 50 strains, 30 strains $(60 \%)$ were observed to possess CTX type of $\beta$ lactamases (Table 3). The other strains may possess other type of $\beta$-lactamases (or) any possess other mechanism to attain resistance status against these antibiotics.

\section{Haemolytic activity}

Regarding haemolytic activity $62 \%$ of clinical strains were positive for haemolysis. Among them 20 $(87 \%)$ of them were from UTI samples, $5(29.41 \%)$ of them were from ENT samples and $6(60 \%)$ of them were from Pus samples, (Table -4).

\section{Plasmid}

Regarding the plasmid profile of the E.coli isolates used in this study plasmids of $>23 \mathrm{~kb}$ were found. In this work plasmids of different types (i.e.) $<10 \mathrm{~kb}$ and $>23 \mathrm{~kb}$ were found in $E$. coli strains analyzed. 10 strains covering all patterns of antibiogram were selected for plasmid study. Their resistance patterns are given in Table -2. One strain which was resistant AMP alone did not possess any plasmid whereas another similar strain possessed 1 plasmid. The resistant patterns of varying nature (resistance up to 4 antibiotics) also possessed only one plasmid. However 2 strains which possessed 4 and 5 plasmids were resistant to all the 5 antibiotics tested and were isolated from UTI patients (Fig. 1 and Table 5).

\section{Plasmid isolation and curing}

Plasmid curing showed interesting results. Towards antibiotics like Ampicillin, Amoxicillin and Cephalosporin's, strains lost their resistance status after plasmid curing. When plasmid curing was done all the resistant strains tested against $\beta$-lactam antibiotics tested in the present investigation lost resistance.

Table 1: Antibiotic resistance percentage

\begin{tabular}{|c|c|c|}
\hline Antibiotic & $\begin{array}{c}\text { No. of strains resistant } \\
\text { for the tested } \\
\text { total of 50 isolates }\end{array}$ & \% of resistance \\
\hline AMP(Ampicillin) & 50 & $100 \%$ \\
\hline AMX(Amoxicillin) & 41 & $82 \%$ \\
\hline CXM(Cefuroxime) & 27 & $54 \%$ \\
\hline CN(Cephalexin) & 29 & $58 \%$ \\
\hline CPD(Cefpodoxime) & 19 & $38 \%$ \\
\hline
\end{tabular}

Table 2: Antibiotic resistance pattern and MAR index

\begin{tabular}{|c|c|c|c|c|c|}
\hline $\begin{array}{l}\text { Sample sources of } \\
\text { the isolates }\end{array}$ & Total No. of isolates & $\begin{array}{c}\text { Source wise } \\
\text { total isolate \% }\end{array}$ & Antibiotic pattern & $\begin{array}{l}\text { Antibiotic } \\
\text { pattern \% }\end{array}$ & $\begin{array}{l}\text { MAR } \\
\text { index }\end{array}$ \\
\hline ENT & 5 & \multirow{2}{*}{ ENT $-30 \%$} & AMP & 10 & - \\
\hline ENT & 5 & & AMX & 10 & - \\
\hline Pus & 3 & \multirow{2}{*}{$\mathrm{UTI}-46 \%$} & AMP-AMX & 6 & 0.4 \\
\hline UTI-4, ENT-2, Pus-2 & 8 & & AMP-AMX-CXM & 16 & 0.6 \\
\hline UTI-5, ENT-2, Pus-3 & 10 & \multirow{3}{*}{ Pus $-10 \%$} & AMP-AMX-CN & 20 & 0.6 \\
\hline UTI-5, ENT-3, Pus-2 & 10 & & AMP-CXM-CN-CPD & 20 & 0.8 \\
\hline UTI & 9 & & $\begin{array}{c}\text { AMP-AMX-CXM-CN- } \\
\text { CPD }\end{array}$ & 18 & 1.0 \\
\hline
\end{tabular}


Table 3: Extended spectrum of Beta lactamase (ESBL)

\begin{tabular}{|c|c|c|}
\hline Strain & ESBL \% & No. of strains tested \\
\hline E.coli from clinical samples & $60 \%$ & $30 / 50$ strains \\
\hline
\end{tabular}

Table 4: Hemolytic activity

\begin{tabular}{|c|c|c|c|c|}
\hline Sample source & No. of isolates & $\begin{array}{c}\text { No. of haemolytic } \\
\text { strains }\end{array}$ & Haemolytic activity \% & $\begin{array}{c}\text { Overall Haemolytic } \\
\text { activity } \%\end{array}$ \\
\hline UTI & 23 & 20 & 87 & \\
\hline ENT & 17 & 5 & 29.41 & 62 \\
\hline Pus & 10 & 6 & 60 & \\
\hline
\end{tabular}

Table 5: Plasmid profile of E. coli isolates from clinical samples

\begin{tabular}{|c|c|c|c|c|}
\hline \multirow[b]{2}{*}{ Strain/Isolate } & \multicolumn{3}{|c|}{ Plasmid size profile (in kb) } & \multirow[b]{2}{*}{ Antibiotic resistant pattern } \\
\hline & $<10 \mathrm{~kb}$ & $>23 \mathrm{~kb}$ & $\begin{array}{c}\text { Total No. } \\
\text { of plasmids }\end{array}$ & \\
\hline 1 & -- & 1 & 1 & AMP \\
\hline 2 & -- & 1 & 1 & AMX \\
\hline 3 & -- & -- & -- & AMP \\
\hline 4 & -- & 1 & 1 & AMP-AMX \\
\hline 5 & -- & 1 & 1 & AMP-AMX-CXM \\
\hline 6 & -- & 1 & 1 & AMP-AMX-CXM \\
\hline 7 & -- & 1 & 1 & AMP-AMX-CXM \\
\hline 8 & $2(9.5,8 \mathrm{~kb})$ & 2 & 4 & AMP-AMX-CXM-CN-CPD \\
\hline 9 & $3(8,5 \cdot 5,3 \mathrm{~kb})$ & 2 & 5 & AMP-AMX-CXM-CN-CPD \\
\hline 10 & -- & 1 & 1 & AMP-CXM-CN-CPD \\
\hline
\end{tabular}

Fig. 1: Plasmid profile of multidrug resistant E.coli isolates isolated from clinical samples

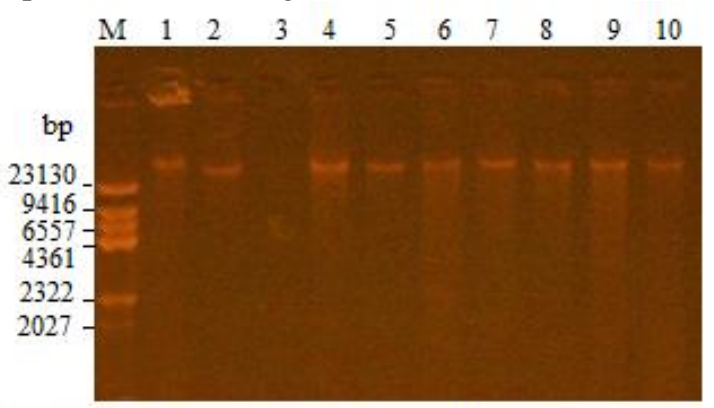

Lane 1-10: Plasmid profile of E.coli isolates isolated from clinical samples Lane M : Lambda DNA Hind III digest - DNA marker

\section{Discussion}

A total of $50 \mathrm{E}$. coli strains were used for testing their antimicrobial susceptibility. Regarding susceptibility of $E$. coli, the resistant and sensitive patterns were tested to 5 antibiotics at a concentration of

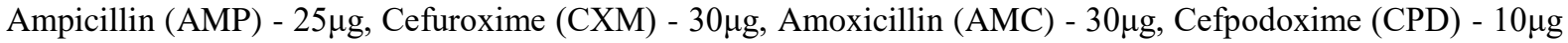

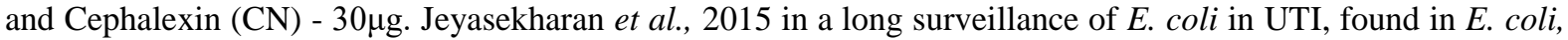
an increasing trend of resistance to gentamycin, cephalosporin and flouroquinolones which were reflected in the results of the present study also.

Sohail et al., 2015 collected pathogenic isolates from patients with UTI in Punjab, in which they observed E. coli was highly resistant to antimicrobial drugs, viz. cephalexin (95\%), cephradine (95\%), pipemidic acid (92\%), amikacin (91\%), and nalidixic acid (91\%). Most of the routine $\beta$-lactam antibiotics like amoxicillin/clavulanic acid, ampicillin, and aztreonam were also ineffective against $E$. coli, with resistance rates of $84 \%, 84 \%$, and $72 \%$, correspondingly.

The present study indicated the presence ESBL production in various E.coli strains which was indicative through exhibited resistance to first, second as well as third generation cephalosporin. Among 50 strains, 30 strains $(60 \%)$ were observed to possess CTX type of $\beta$-lactamases. The other strains may possess other type of $\beta$-lactamases (or) any possess other mechanism to attain resistance status against these antibiotics. According to a study previously performed in Beirut (Daoud and Afif, 2011), E. coli was the most frequent isolate (60.64\% of the total isolates) and an increase in the production of ESBL was observed between the years 2000 and 2009 (2.3-16.8\%). Unfortunately, very limited data concerning UTIs is available from other regions of the country. In Indian context also studies are limited. 
The highest MAR index of 1.0 in $18 \%$ of strains in the present investigation emphasizes the public health risk under study. Boon and Catlanach (1999) observed the antibiotic resistance of THB which was greater than that of E.coli in river samples of Victoria region of Australia.

In the present investigation the strains were resistance to the $\beta$-lactam antibiotics including cephalosporin. Agwu and Oluwagunke (2014) also recorded resistance to $\beta$-lactam antibiotics such as ampicillin and amoxicillin in surface water E.coli isolates were high (i.e.) respectively 96 and $88 \%$.

Only few studies reported this much higher resistance (Lobova et al., 2008 and Al-Hussaini et al., 2012). However in general among $\beta$-lactam antibiotic ampicillin and amoxicillin showed higher resistance compared to other group of antibiotics (Sivri et al., 2012; Mehta et al., 2012 and Rehman et al., 2013).

Plasmid curing was done all the resistant strains tested against $\beta$-lactam antibiotics tested in the present investigation lost resistance. Plasmid is one of the important mediators for fast spreading of antibiotic resistance in bacteria (Datta and Park, 2004).

\section{Conclusion}

The results obtained in this study clearly showed that the 5 different antibiotics (Ampicillin, Amoxicillin, Cefuroxime, Cephalexin, and Cefpodoxime) were tested to study the antimicrobial susceptibility of the E.coli isolates. In this research work not to all the $\beta$-lactam antibiotics, the E.coli strains were equally resistant. Though $100 \%$ resistance was observed against ampicillin, only $50 \%$ resistance was observed regarding amoxicillin. When plasmid curing was done all the resistant strains tested against $\beta$-lactam antibiotics tested in the present investigation lost resistance. By performing this study we can extend further research to manage common and lethal bacterial infections, critically compromised by the appearance and the rapid spread of antibiotic resistant bacteria and to begin the process of developing actionable policy recommendation relevant to low and middle income countries.

\section{Acknowledgements}

The authors are grateful to Dr. Jayalakshmi for providing necessary facilities.

\section{References}

[1] Agwu, O.A and O. Oluwagunke, 2014. Pattern of multiple antibiotics resistance among surface water Escherichia coli. Adv. Life Sci., 4(5): 213-219.

[2] Balagué, C. and E.García-Véscovi, 2001. Cultivation of multiple antibiotic resistances in uropathogenic Escherichia coli strains by aryloxoalcanoic acid compounds. Antimicrob. Agents Chemother, 45: 1815-1822.

[3] Beutin, L., M. A. Montenegro, I. Ørskov, F. Ørskov, J. Prada, S. Zimmermann and R. Stephan, 1989. Close association of verotoxin (shiga-like toxin) production with enterohemolysin production in strains of Escherichia coli. J. Clin. Microbial, 27: 2559-2564.

[4] Bonnet, R., 2004. Growing group of extended-spectrum beta-lactamases: the CTX-M enzymes. Antimicrob. Agents Chemother, 48: $1-14$.

[5] Boon, P. I., and M. Cattanach. 1999. Antibiotic resistance of native and faecal bacteria isolated from rivers, reservoirs and sewage treatment facilities in Victoria, south-eastern Australia. Lett. Appl. Microbiol., 28:164-168.

[6] Bush, K., 2010.Bench-to-bedside review: The role of $\beta$-lactamases in antibiotic-resistant Gram-negative infections. Crit. Care, 14(3): p. 224.

[7] Daoud, Z. and C. Afif, 2011. Escherichia coli isolated from urinary tract infections of Lebanese patients between 2000 and 2009: epidemiology and profiles of resistance. Chemother. Res. Pract.10: 1-6.

[8] Datta, P., A.Thakur, B. Mishra and V. Gupta, 2004. Prevalence of clinical strains resistant to various beta lactamase in a tertiary care hospital in India. Jpn. J .Infect. Dis., 57:146-149.

[9] Duttaroy, B. and S. Mehta, 2005. Extended spectrum $\beta$-lactamases (ESBL) in clinical isolates of Klebsiella pneumoniae and Escherichia coli. Ind.J. Pathol. Microbiol, 48(1):45-48.

[10] Fugii, T., M. Takeo and Y. Maeda, 1997. Plasmid-encoded genes specifying aniline oxidation from Acinotobacter sp strain YAA. Microbiol., 143:93-99.

[11] Fugii, T., M. Takeo and Y. Maeda, 1997. Plasmid-encoded genes specifying aniline oxidation from Acinotobacter sp strain YAA. Microbiol, 143:93-99.

[12] Goering, R.V., 2008. Mims' Medical Microbiology. 4th ed. Mosby Elsevier.

[13] Goñi-Urriza, M., M.Capdepuy, C.Arpin, N.Raymond, P. Caumette and C.Quentin, 2000.Impact of an urban effluent on antibiotic resistance of riverine Enterobacteriaceae and Aeromonas spp. Appl. Environ. Microbial, 66 (1): 125-132.

[14] Greenwood, D., 1998. Resistance to antimicrobial agents: A personal view. J. Med. Microbiol., 47:751-5.

[15] Jacoby, G.A., 2009.AmpC $\beta$-lactamases. Clin. Microbiol. Rev., 22(1): p. 161-82.

[16] Jeyasekharan, D.D., R Nelson Manohar, R Devaprasath, M Andreas, B Bhatia, 2015. Long-term surveillance of Escherichia coli antibiotic resistance patterns in urinary tract infections in a southern India hospital. 1(4): 264.267.

[17] Lobova, T.I., V.Y. Barkhatov, V.O. Salamatina and L. Y.Popovad, 2008. Multiple antibiotic resistances of heterotrophic bacteria in the littoral zone of lake Shira as an indicator of human impact on the ecosystem. Microbiol. Res., 163: 152-160.

[18] McArthur, J.V. and R.C.Tuckfield, 2000. Spatial patterns in antibiotic resistance among stream bacteria: Effects of industrial pollution. Appl. Environ.Microbiol., 66 (9): 3722-3726.

[19] Mehta, M., S. Bhardwaj and J.Sharma, 2012.Prevalence and antibiotic susceptibility pattern of multi-drug resistant Escherichia coli isolates from urinary tract infection (UTI) patients. 2(4): L6-L11.

[20] Poole,L., R. B. Harvey, J. A. Byrd and D. J. Nisbet. 2004. Effects of sodium chlorate on toxin production by Escherichia coli O157:H7. Curr. Issues Intestinal Microbiol, 5: 19-22.

[21] Rehman, M.U., M. Rashid, J.A. Sheikh, S.A. Wani and S. Farooq, 2013. Multi-drug resistance among shiga toxin producing Escherichia coli isolated from bovines and their handlers in Jammu region. India Vet. World, 6: 655-658. 
[22] Rossolini, G.M. and E.Mantengoli, 2008. Antimicrobial resistance in Europe and its potential impact on empirical therapy. Clin .Microbial. Infect. 14 (6): 2-8

[23] Sambrook, J., E.F.Fritsch and T. Maniats, 1989. Molecular cloning: A laboratory manual. 2. ed. New York, Cold Spring Harbor Laboratory. 1-28.

[24] Sivri, N., C. Sandalli, O.B. Ozgumus, F.Colakoglu and D.Dogan, 2012. Antibiotic resistance profiles of enteric bacteria isolated from Kucukcekmece Lagoon (Istanbul-Turkey).Turk. J. Fish. Aquat. Sci., 12: 699-707.

[25] Slama, K.B., A.Jouini, R.S.Sallem, S.Somalo, Y.Saenz, V.Estepa, A.Boudabous and C. Torres, 2010. Prevalence of broadspectrum cephalosporin-resistant Escherichia coli isolates in food samples Tunisia and characterization of integrons and antimicrobial resistance mechanisms implicated. Int. J. Food Microbiol, 137:281- 286

[26] Sohail, M., M. Khurshid, H.G. Saleem, H. Javed and A.A. Khan, 2015. Characteristics and antibiotic resistance of urinary tract pathogens isolated from Punjab, Pakistan. Jundishapur J. Microbiol., 8(7):e19272.

[27] Srisangkaew, S. and M. Votachit, 2004. The optimum agent for screening and confirmatory tests for extended-spectrum betalactamases in Escherichia coli and Klebsiella pneumoniae in Ramathibodi Hospital. Thailand. J.Infect. Dis. Antimicrob. Agents. 21 (1): $1-5$.

[28] White, D.G., L.J.V. Piddock, J.J. Maurer, S.Zhao, V. Ricci and S.G.Thayer, 2000. Characterization of fluoroquinolone resistance among veterinary isolates of avian Escherichia coli. J. Antimicrobiol., Agents Chemother, 44 (10): 2897-2899.

IOSR Journal of Pharmacy and Biological Sciences (IOSR-JPBS) is UGC approved Journal with Sl. No. 5012, Journal no. 49063.

Sujatha. J. "Prevalence of Antibiotic Resistance in Clinical Strains of E. Coli and Their Control." IOSR Journal of Pharmacy and Biological Sciences (IOSR-JPBS) 12.4 (2017): 28-33. 